\title{
Investigation of Woven Composites as Potential Cryogenic Tank Materials
}

\author{
Md S. Islam, E. Melendez-Soto, A.G. Castellanos, P. Prabhakar* \\ Department of Mechanical Engineering, University of Texas, El Paso, TX 79968
}

\begin{abstract}
In this paper, carbon fiber and $\operatorname{Kevlar}^{\circledR}$ fiber woven composites were investigated as potential cryogenic tank materials for storing liquid fuel in spacecraft or rocket. Towards that end, both carbon and Kevlar ${ }^{\circledR}$ fiber composites were manufactured and tested with and without cryogenic exposure. The focus was on the investigation of the influence of initial cryogenic exposure on the degradation of the composite. Tensile, flexural and inter laminar shear strength (ILSS) tests were conducted, which indicate that Kevlar ${ }^{\circledR}$ and carbon textile composites are potential candidates for use under cryogenic exposure. Keywords: A: Woven Composites; B: Cryogenic Exposure; C: Polymer Matrix Composites; D: Thermosetting
\end{abstract}

\section{Introduction}

The field of composite materials has gained importance within the study of engineering in the recent years. Developments in material science and the study of novel materials have allowed engineers to consider the use of alternative and less traditional materials in their designs. Composite materials have been known for providing good strength to weight ratios, improved thermal and mechanical properties, and many other desirable aspects which are obtained through the combination of different constituent materials. Among myriad applications of composite materials like aircraft and naval

\footnotetext{
*Corresponding author. Tel.: 9157475863

Email address: pprabhakar@utep.edu (P. Prabhakar)
} 
structures, automobiles, medical devices, etc., their use in cryogenic fuel tanks could result in an increase in the efficiency of the system.

Cryogenic tanks are commonly used to store extremely low temperature fluids, like liquid oxygen $\left(-183^{\circ} \mathrm{C}\right)$, liquid methane $\left(-161^{\circ} \mathrm{C}\right)$ or liquid hydrogen $\left(-252^{\circ} \mathrm{C}\right)$ in their condensed form in order to generate highly combustible liquids. This type of tank, generally composed of different layers of insulators and some type of metal liners [1, 2], is exposed to an extremely cold temperature in its interior and to ambient temperature on its external surface. A large temperature gradient across the thickness of the wall often cause differential expansion and contraction across the tank walls, resulting in an uneven expansion or contraction of the material. If the stresses caused by this differential expansion exceed the strength of the material, cracks initiate and propagate in the direction of least resistance. In addition, if the boundaries of the material do not impede crack propagation, this will ultimately cause the tanks structure to fail, resulting in an undesirable leakage [3] that will consequently lead to the catastrophic fuel tank failure in the case of a rocket or spacecraft being launched into space.

National Aeronautics and Space Administration (NASA) recently (August 2014) completed a major space technology development milestone by successfully testing a large pressurized cryogenic propellant tank made of composite material [1]. The advancements made in the scope of composite materials have allowed for improvements in designs that were restrained in the past by a limited material selection. In the case of NASA, switching from metallic to composite construction has the potential to dramatically increase the performance capabilities of future space systems through a significant reduction in weight $[1,2,4]$. The applications and benefits that could be derived from further developing composite materials for cryogenic applications are countless. It would be of paramount interest to design better composite material systems, like textile composites that have superior structural $[5,6,7,8,9,10]$ and thermal properties compared to traditional laminates, as well as better draping compared to continuous fiber reinforced composites $[8,10]$. Draping is the ability of woven textile 
fabric to conform to complex curved shapes, that is, regardless of the weave pattern, the fabric tows rotate freely to take the shape of the underlying structure [11]. Further, study by Potter [12] on the influence of stretching/draping of various reinforcements, like woven fabric (textiles), unidirectional and cross-ply layers on complex geometry has shown that the slippage capability between tows in woven fabric allows for more stretch/easy draping compared to others without applying undue force..

Previous research regarding the use of composite materials as cryogenic tank materials mainly dealt with thermal cycling of unidirectional composites, and their damage behavior and permeability under fatigue-thermal loads $[13,14,15,16,17,18,19,20$, 21, 22]. Gong et al. [23] studied the mechanical properties of unidirectional E-glass fiber/epoxy and carbon fiber/epoxy laminates at cryogenic temperature and Disdier et al. [24] studied helium permeation on woven E-glass fabric composites. Verstraete et al. [25] investigated hydrogen fuel tank with foam core and multilayer insulations (MLI) along with aluminum tank wall and composite fairing. Aceves et al. [26] explored aluminum-lined, fiber wrapped cryogenic hydrogen storage tank at different temperature and pressure cycles. Shindo et al. [27] evaluated the interlaminar shear strength (ILSS) of G-10CR glass-cloth/epoxy laminates at room temperature, $77 \mathrm{~K}$ and $4 \mathrm{~K}$ temperatures and found a slight increase in ILSS with reduced temperature. Further, Kumar et al. [28] probed the influence of cryogenic conditioning of woven carbon/epoxy laminates and found a reduction in ILSS at high fiber volume fraction.

NASA's Composite Overwrapped Pressure Vessel (COPV refer to Fig. 1(a)) is a well established cryogenic tank with metallic liner and continuous fiber/matrix system wrapped around it (refer to Fig. 1(b)). The main purpose of liner in cryogenic tanks is to prevent or minimize the permeation of cryogenic liquid through the walls of the external structure as well as minimize thermal stresses. Embrittlement in metallic liners and significant mismatch in coefficient of thermal expansion between liner and tank structure pose issues of microcracking in liner and delamination between the two [29]. Therefore, if an unlined composite tank structure is designed efficiently to prevent 


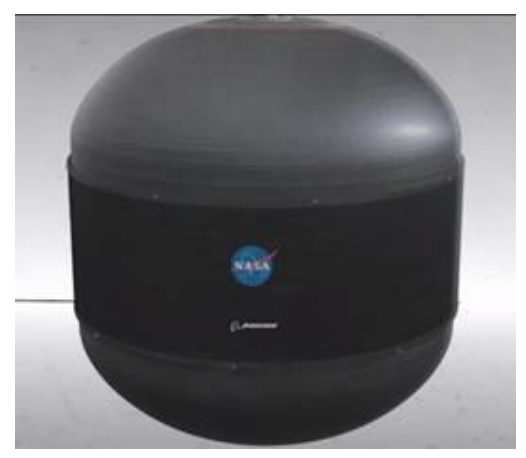

(a)

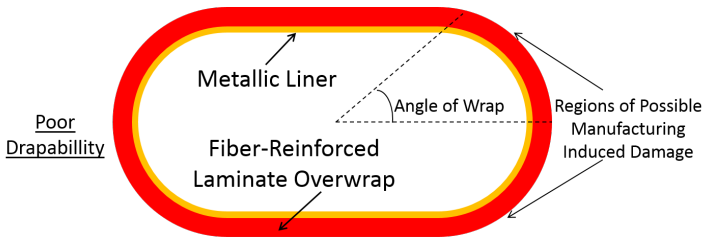

(b)

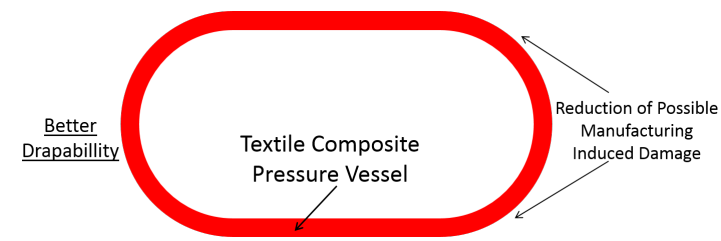

(c)

Figure 1: (a) NASA's Composite Cryogenic Fuel Tank, (b) Schematic of Fiber-Reinforced Laminate Overwrap and (c) Schematic of Textile Composite Pressure Vessel

possible microcracking while maintaining the overall structural integrity will result in lightweight cryogenic tanks. The overarching goal of the study conducted in this paper is to design cryogenic tanks without metallic liner or insulator, thus, further reducing the overall weight of the cryogenic tank while sustaining cryogenic temperatures and in-service mechanical loads. Towards that end, the feasibility of using textile composites was investigated in this paper. Textile composites have better drapability $[8,10]$, which would potentially result in smaller (localized) regions of damage that might occur around bends and edges in a pressure vessel (refer to Fig. 1(c)).

Designing unlined cryogenic composite tank materials is extremely challenging. The extreme temperature on the walls could result in damage in the material, thereby, reducing the safety and reliability of the tank. Failure modes, like delamination, transverse cracking, micro-buckling etc. within fiber reinforced laminates caused by the exposure to cryogenic temperatures may result in undesirable leakage and catastrophic failure [30]. That is, mismatch in the coefficient of thermal expansion between the layers and 
the interlaminar matrix region may initiate delamination between the layers. Further, the inter-tow matrix regions may experience stress concentration due to mechanical and thermal property mismatch, causing transverse micro-cracking within the layers of the composite. Therefore, it is extremely important to investigate the failure and damage behavior of such composites subjected to cryogenic temperatures. Therefore, the focus of this paper is to explore the possibility of using textile composites for constructing cryogenic fuel tanks by unveiling their response to cryogenic exposure.

The influence of cryogenic exposure on the stiffness and strength of woven carbon and Kevlar ${ }^{\circledR}$ fiber reinforced composites each are experimentally investigated as potential materials for constructing unlined cryogenic tanks. The paper is divided into the following sections: Experimental procedure that includes the details on the manufacturing process, cryogenic exposure and mechanical testing methodology; Discussion of results from the mechanical tests; Pictographic analysis of the material post cryogenic exposure and mechanical testing, followed by conclusions.

\section{Experimental Procedure}

\subsection{Material System}

Dry fabrics of woven (plain weave) carbon fiber and Kevlar ${ }^{\circledR}$ fiber tows were used as reinforcement with Epon 862/ Epikure 9553 hardener as matrix material. The carbon and Kevlar ${ }^{\circledR}$ fabric were purchased from fibreglast.com and their properties are given in Table 1. The hardener was mixed with the resin at a ratio (weight) of 16.9:100 as recommended by the manufacturer.

\subsection{Manufacturing Process: Vacuum Assisted Resin Transfer Molding}

Vacuum Assisted Resin Transfer Molding (VARTM) process is an advanced fabrication process for polymer-matrix textile composite structures. It is very cost effective to produce large scale composites while maintaining the quality of the final composite $[7,31,32,33,34]$. Fig. 2 provides an overview of the VARTM process. Dry fabric was 
Table 1: Fabric properties (fibreglast.com)

\begin{tabular}{|c|c|c|}
\hline \hline Properties & Carbon Fabric & Kevlar $^{\circledR}$ Fabric \\
\hline Warp Raw Material & 3K-Multifilament Continious Tow & 1140 denier Kevlar $\left.{ }^{(}\right) 49$ \\
\hline Filling Raw Material & 3K-Multifilament Continious Tow & 1140 denier Kevlar ${ }^{(} 49$ \\
\hline Weave Pattern & Plain Weave & Plain Weave \\
\hline Warp Ends/Inch (approx.) & $12.5 \pm 1.0$ & 17 \\
\hline Fabric Areal Weight & $5.4-5.9 o z / y d^{2}$ & $5.3 o z / y d^{2}$ \\
\hline Nominal Thickness & 0.012 inches & 0.011 inches \\
\hline
\end{tabular}

first placed between two metal plates along with nylon release peel ply, flow media and breathers (refer to Fig. 2(a)). Since, woven fabric was used, there is no ply orientation associated with it. However, the layers were arranged such that the direction of tows in different layers were parallel to each other. The complete mold (Fig. 2(b)) was then enclosed in a vacuum bag and the preform was impregnated with resin through an inlet port and transferred into the preform by a pressure gradient induced by a vacuum pressure. The dry fabric preform were debulked under vacuum prior to resin infusion, and the resin was allowed to settle down until most bubbles were at the top of the mixing bowl. After infusing the resin, the mold was placed inside an oven for curing $[7,32,35]$. For the current material system, the resin was cured at room temperature for 24 hours. The manufactured laminate was transversely isotropic and the approximate fiber weight fraction for carbon and Kevlar ${ }^{\circledR}$ fiber was $37 \%$ and $43 \%$, respectively. In the current study, the main objective was to explore the feasibility of these composites to sustain cryogenic temperatures overall. A future work will investigate the effect of temperature gradient through the thickness of the tank wall.

\subsection{Exposure to Cryogenic Environment}

The composite specimens were exposed to cryogenic environment by submerging them in a container (Fig. 3(a)) filled with liquid nitrogen $\left(L N_{2}\right)$ at a temperature of $-196^{\circ} \mathrm{C}(77 \mathrm{~K})$. Although, the actual fuel to be stored in the tank might be liquid methane or oxygen, nitrogen was used because it is easier to handle and possesses 


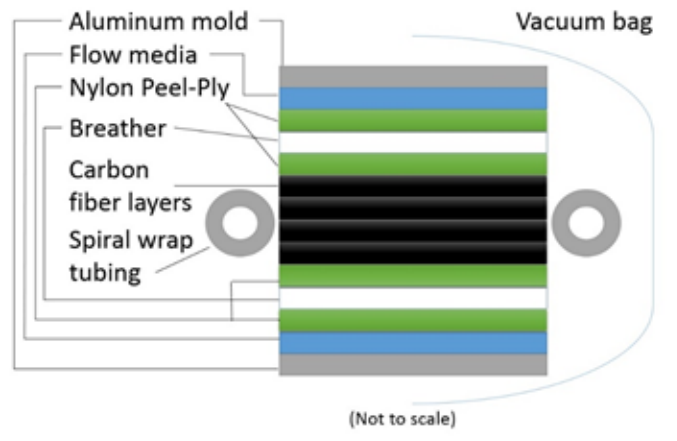

(a)

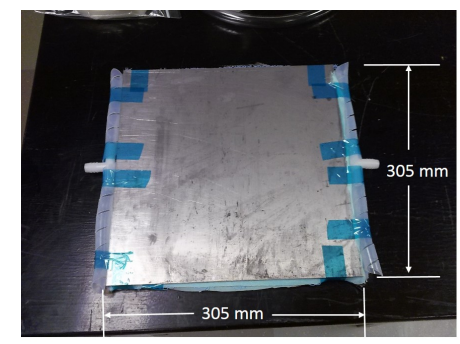

(b)

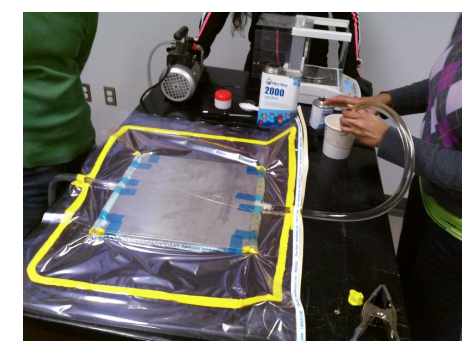

(c)

Figure 2: VARTM process: (a) Material Layup for the Mold; (b) Mold with Dry Fabric; (c) Vacuum Bag with Resin Infusion

temperature similar to the others in its liquid state. The test specimens were exposed to $L N_{2}$ for 6 hours, which is approximately twice the time taken to fill up a X-33 liquid hydrogen tank $[36,37]$. The specimens were then subjected to tensile and flexural loading after allowing them to return to room temperature upon removal from the cryogenic container. It is hypothesized that the initial exposure to cryogenic environment would have an adverse effect on the stiffness and/or strength of the composite. That is, the matrix tends to deform (shrink and harden) after cryogenic conditioning, but, is resisted by the stiff fibers causing residual stresses at the fiber/matrix interface resulting in transverse cracks and debonds.

\subsection{Tensile Tests}

Tensile tests on the two types of composites (carbon and Kevlar ${ }^{\circledR}$ reinforced) were conducted. A total of 16 samples (8 of each material type) were prepared for the tensile tests according to ASTM D3039 standard [38]. Tensile test specimens were cut 


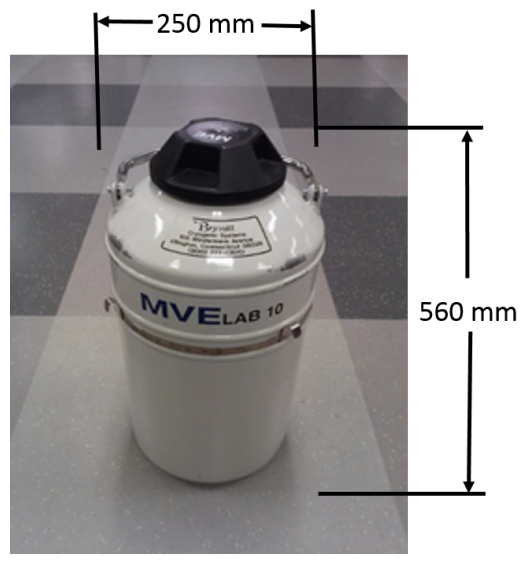

(a)

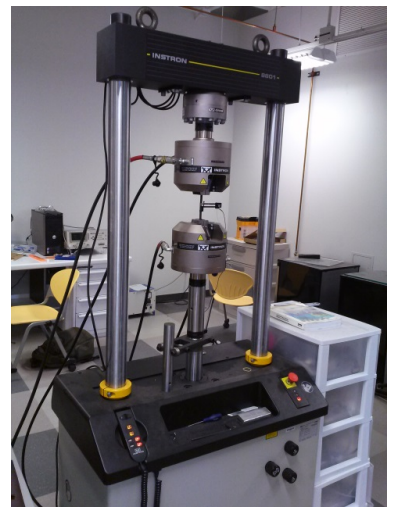

(b)

Figure 3: (a) Cryogenic Exposure Container; (b) Instron Test Frame

parallel to the tow direction with the following dimensions: length $250 \mathrm{~mm}$ x width $25 \mathrm{~mm} \mathrm{x}$ thickness $1.2 \mathrm{~mm}$. During the test, specimens were loaded in the Instron 8801 Servohydraulic Fatigue Testing System (Fig. 3(b)) at a loading rate of $2 \mathrm{~mm} / \mathrm{min}$ until failure. The load-displacement reponses were determined for each case, and the corresponding tensile stress-strain responses were calculated using the area of crosssection and the gauge length $(25 \mathrm{~mm})$ of the extensometer (Instron 2620-601). Four specimens each of carbon and Kevlar ${ }^{\circledR}$ materials were tested as pristine and the other four were exposed to liquid nitrogen for 6 hours and then tested.

\subsection{Flexural Test}

Three-point bending tests were carried out on both carbon and Kevlar ${ }^{\circledR}$ composite specimen to determine the flexural properties of the composites. A total of 8 specimens (4 pristine and 4 cryogenic exposed) were tested for both carbon and Kevlar ${ }^{\circledR}$ fiber composites each according to ASTM D7264 standard [39]. Specimens were cut parallel to the tow direction and dimensions were: length $150 \mathrm{~mm}$ x width $13 \mathrm{~mm} \mathrm{x}$ thickness for carbon composite was $3.3 \mathrm{~mm}$ and for Kevlar ${ }^{\circledR}$ composite was $4.33 \mathrm{~mm}$. Three point bending tests were also carried out on the same Instron 8801 machine at a loading rate of $1 \mathrm{~mm} / \mathrm{min}$. A constant span length to width ratio of 32:1 maintained for both types 
of composites that resulted in a span length of $105 \mathrm{~mm}$ and $138 \mathrm{~mm}$ for carbon and Kevlar ${ }^{\circledR}$, respectively. The total length of the specimen for Kevlar ${ }^{\circledR}$ fiber was less than the specified value in ASTM D7264. In order to calculate the flexural chord modulus of elasticity, strain range from 0.001 to 0.003 was selected from the stress-strain diagram as recommended in ASTM D7264 [39].

\subsection{Short Beam Shear Test}

Short Beam Shear (SBS) tests were conducted next to measure the Interlaminar Shear Strength (ILSS) of the composite. The total number of specimens tested were the same as mentioned in section 2.4 and 2.5. The specimens were prepared according to ASTM D2344 standard [40] with specimen dimensions of length $40 \mathrm{~mm}$ x width $12.36 \mathrm{~mm}$ x thickness $5.87 \mathrm{~mm}$ for carbon fiber and length $40 \mathrm{~mm}$ x width $12.81 \mathrm{~mm}$ $\mathrm{x}$ thickness $6.35 \mathrm{~mm}$ for Kevlar ${ }^{\circledR}$ fiber. SBS tests were also carried out on the same Instron 8801 machine with a loading rate of $1.0 \mathrm{~mm} / \mathrm{min}$.

\section{Results and Discussion}

Woven composites with carbon and Kevlar ${ }^{\circledR}$ fiber tows as stiffeners were investigated in this paper in order to understand their respective mechanical behaviors upon cryogenic exposure for 6 hours as mentioned in section 2.3. Results from the different experimental investigations mentioned above are discussed in this section. It should be noted that, tensile properties are fiber dominated, which implies that influence of degradation of matrix on tensile properties are not as evident as that on flexural properties. Flexural properties are matrix dominated, which means that the shear loading induced in the matrix in the compression region during flexural deformation of the composite acts as a catalysis for micro-buckling type failure in the fiber tows and splitting/delamination type failure along the load direction [41, 42]. Therefore, matrix degradation manifests itself at the composite scale by reducing the flexural properties of a composite more compared to tensile properties. That is, due to the fiber dominated 
nature of tensile loading, minimal property loss would be expected from any delamination damage. Flexural and ILSS testing is much more sensitive to delamination damage that would typically result in a slight to moderate reduction in modulus and moderate to severe reduction in flexural strength.

\subsection{Tension Test Results}

As stated in Section 2.4, tension tests were conducted to determine and compare the material responses with and without cryogenic exposure. Fig. 4 displays the tensile chord modulus and tensile strength of both carbon and Kevlar ${ }^{\circledR}$ composites in both pristine and cryogenic conditions. It was observed that the cryogenic exposure does not have significant influence on the tensile chord modulus and ultimate tensile strength for both carbon and Kevlar ${ }^{\circledR}$ laminates which is summarized in Table 2. It was observed that the tensile chord modulus remains unaltered while the tensile strength reduced by $2.6 \%$ (refer to Table 2) for carbon composite after cryogenic exposure. Whereas, the initial stiffness reduced by $4.5 \%$ while the tensile strength reduced by only $1.7 \%$ for Kevlar ${ }^{\circledR}$ composite.

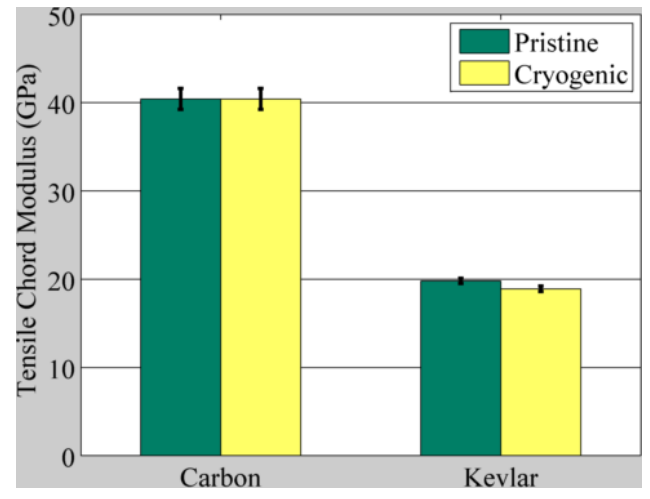

(a)

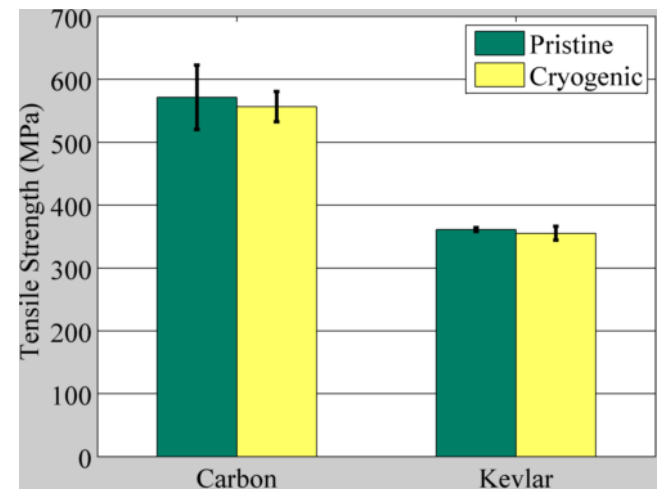

(b)

Figure 4: Bar Chart showing (a) Tensile Chord Modulus and (b) Tensile Strength for both Composites with Standard Deviation

\subsection{Flexural Test Results}

Flexural response of the two types of composites upon exposure to cryogenic conditions is compared to pristine material response. Fig. 5 shows the flexural chord modulus 
Table 2: Tensile test results with standard deviation

\begin{tabular}{|c|c|c|c|c|c|}
\hline \hline Material & Condition & $\begin{array}{c}\text { Tensile Chord } \\
\text { Modulus (GPa) }\end{array}$ & \% Reduction & $\begin{array}{c}\text { Tensile } \\
\text { Strenth (MPa) }\end{array}$ & \% Reduction \\
\hline Carbon & Pristine & $40.4 \pm 1.2$ & - & $571 \pm 51$ & - \\
\hline Carbon & Cryogenic & $40.4 \pm 1.2$ & 0 & $556 \pm 24$ & 2.6 \\
\hline Kevlar $^{\circledR}$ & Pristine & $19.8 \pm 0.3$ & - & $361 \pm 3$ & - \\
\hline Kevlar $^{\circledR}$ & Cryogenic & $18.9 \pm 0.3$ & 4.5 & $355 \pm 11$ & 1.7 \\
\hline
\end{tabular}

and flexural strength of both carbon and Kevlar ${ }^{\circledR}$ composite from the 3-point bending test. It was observed from Fig. 5(a) and Fig. 5(b) that the flexural properties do not change significantly after cryogenic exposure. Table 3 summarizes the results from the flexural tests. The flexural chord modulus and strength reduced by $3.7 \%$ and $3.5 \%$, respectively for carbon composite. Whereas, for Kevlar ${ }^{\circledR}$ composite, the flexural chord modulus and strength reduced by $1.2 \%$ and $1.9 \%$, respectively.

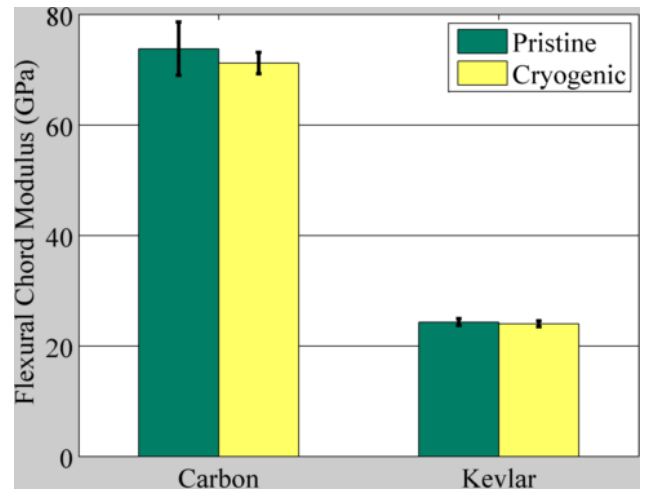

(a)

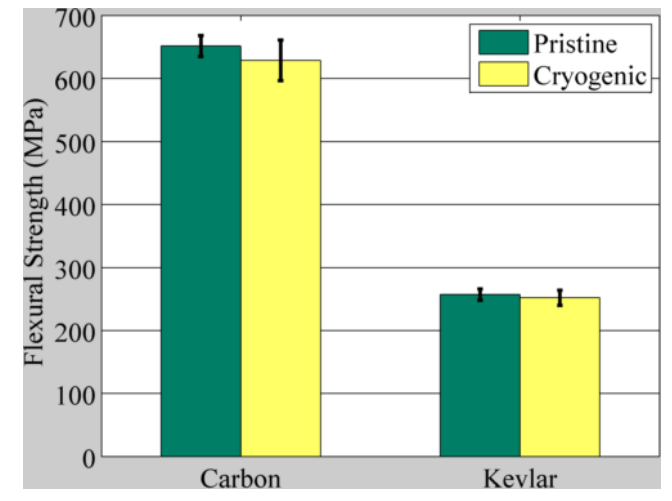

(b)

Figure 5: Bar Chart showing (a) Flexural Chord Modulus and (b) Flexural Strength for both Composites with Standard Deviation

Table 3: Three point bending test results with standard deviation

\begin{tabular}{|c|c|c|c|c|c|}
\hline \hline Material & Condition & $\begin{array}{c}\text { Flexural Chord } \\
\text { Modulus (GPa) }\end{array}$ & \% Reduction & $\begin{array}{c}\text { Flexural } \\
\text { Strenth (MPa) }\end{array}$ & \% Reduction \\
\hline Carbon & Pristine & $73.8 \pm 4.8$ & - & $651.0 \pm 16.7$ & - \\
\hline Carbon & Cryogenic & $71.1 \pm 1.9$ & 3.7 & $628.1 \pm 32.3$ & 3.5 \\
\hline Kevlar $^{\circledR}$ & Pristine & $24.3 \pm 0.6$ & - & $257.1 \pm 8.9$ & - \\
\hline Kevlar $^{\circledR}$ & Cryogenic & $24.0 \pm 0.5$ & 1.2 & $252.1 \pm 11.9$ & 1.9 \\
\hline
\end{tabular}




\subsection{SBS Test Results}

SBS tests were conducted to determine the ILSS of the composites. Fig. 6 shows the ILSS of both types of composites, where the ILSS values for carbon fiber composites do not change significantly after cryogenic exposure, while it reduced by $16.8 \%$ for Kevlar ${ }^{\circledR}$ fiber composites.

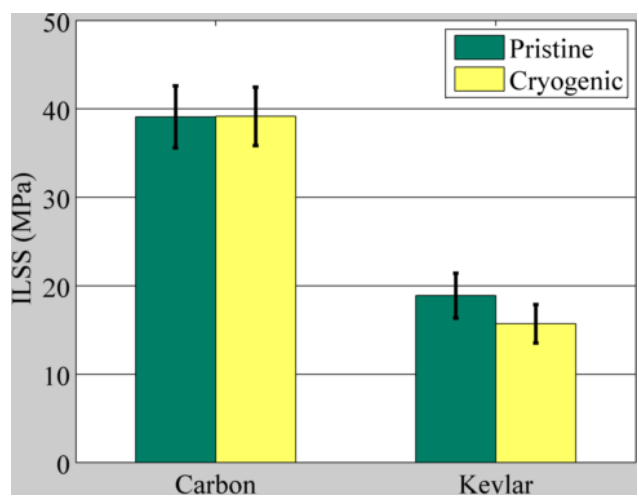

Figure 6: Bar Chart showing ILSS for both Composites with Standard Deviation

\section{Pictographic Analysis}

Further analysis of the samples exposed to cryogenic conditions followed by mechanical loading was conducted to explore the corresponding failure mechanisms. Carbon and Kevlar ${ }^{\circledR}$ composite samples (pristine and exposed) were analyzed using Scanning Electron Microscope (SEM). Figures 7 and 8 show the SEM $(12 \mathrm{kV}$ potenial and same condition was used to take all the images) images of surfaces of carbon and Kevlar ${ }^{\circledR}$ composites of pristine and cryogenic exposed samples. Evidently, there were no growth or propagation of cracks in either case. There was hardly any surface matrix degradation observed and hence the figures look almost the same. Also, their failure modes were similar. The reduction in mechanical properties was negligible under tensile loading and within $4 \%$ under flexural loading as discussed in section 3.1 and 3.2 .

Microscopic analysis of the polished cross-section of the failed specimens from the flexural tests was conducted. Fig. 9(a) (pristine) and Fig. 9(b) (cryogenic exposed) 


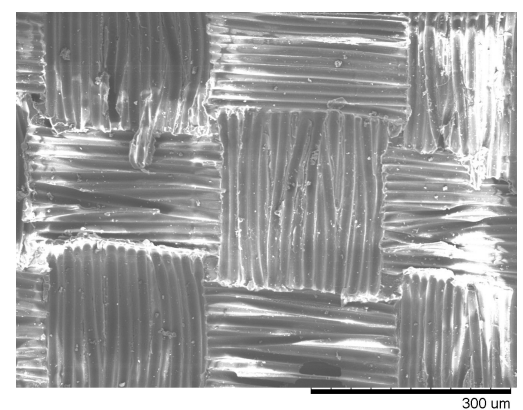

(a)

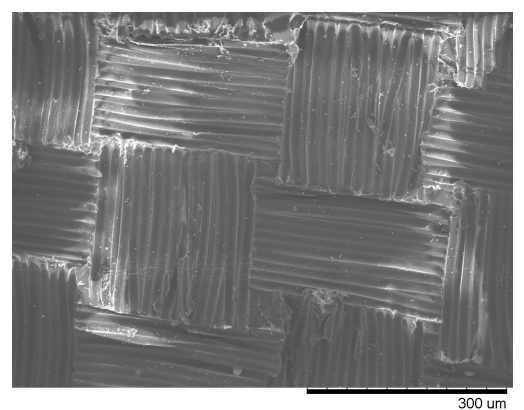

(b)

Figure 7: Scanning Electron Microscope (SEM) Images of Carbon Composite (a) at Room Temperature; (b) after Cryogenic Exposure

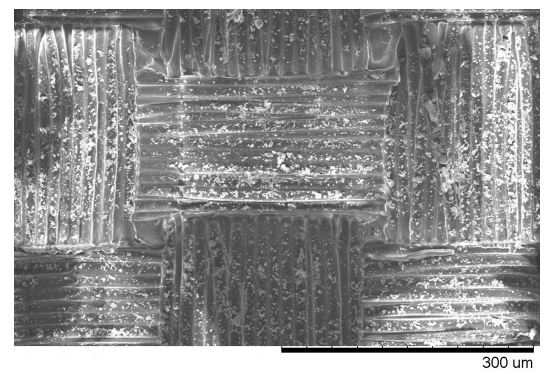

(a)

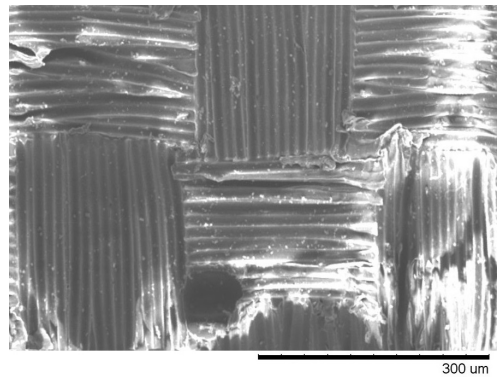

(b)

Figure 8: Scanning Electron Microscope (SEM) Images of Kevlar ${ }^{\circledR}$ Composite (a) at Room Temperature; (b) after Cryogenic Exposure

show the optical microscope images of failed carbon specimen after 3-point bending test. It is observed that failure patterns are similar in both the specimens that failed due to the formation of kink band under the loading point (region A on Fig 11) which is accompanied by fiber breakage of brittle carbon fiber tows. In the case of Kevlar ${ }^{\circledR}$ composite (Fig. 10), the specimens failed due to the formation of shear band with rotated Kevlar ${ }^{\circledR}$ fiber tows under the load point of the specimen (region A on Fig 11). The failure patterns remain unaltered in the pristine and cryogenic exposed specimen.

\section{Conclusions}

Woven fiber reinforced (carbon and $\operatorname{Kevlar}^{\circledR}$ ) composite materials exposed to cryogenic environment were investigated in this paper with the objective of using them in 


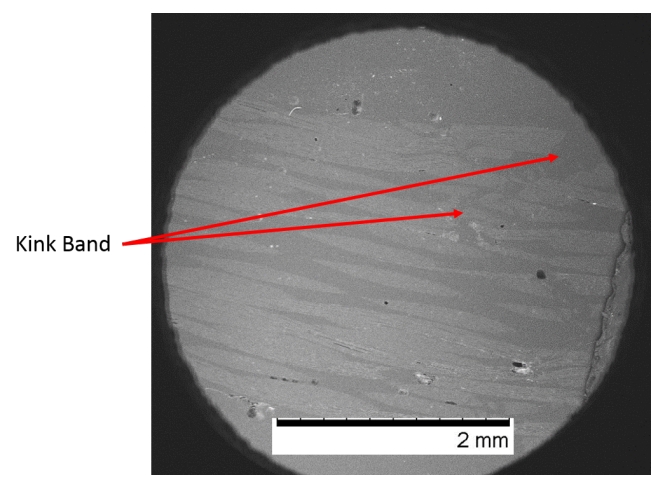

(a)

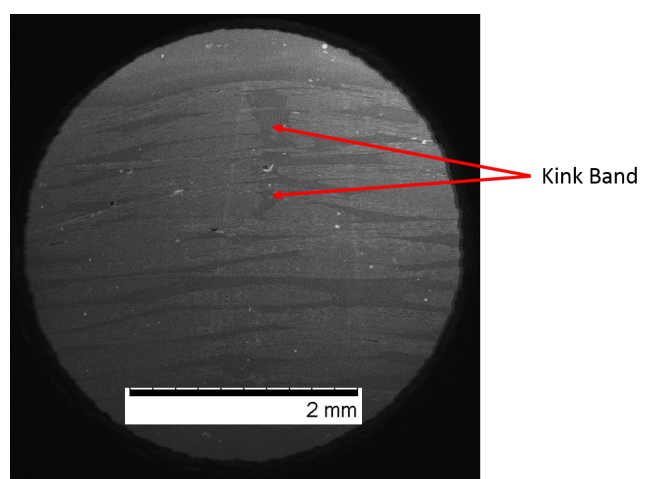

(b)

Figure 9: Optical Microscope Images of Failed Carbon Composite (a) at Room Temperature; (b) after Cryogenic Exposure

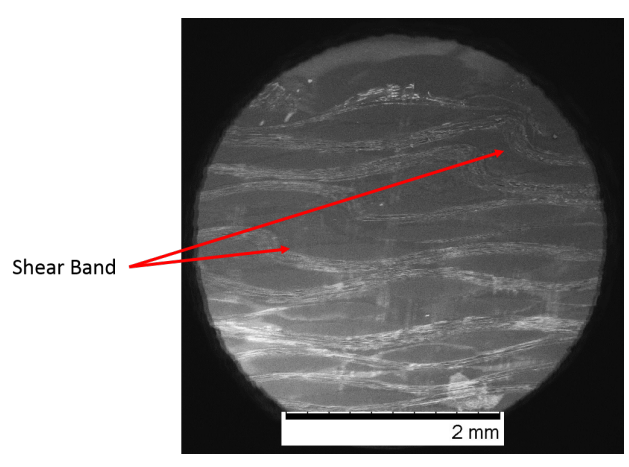

(a)

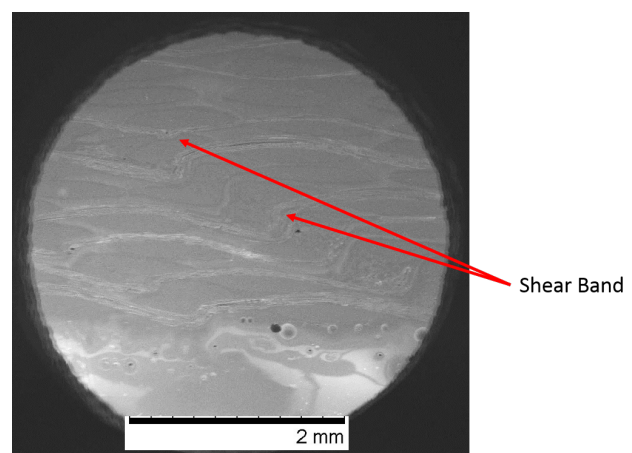

(b)

Figure 10: Optical Microscope Images of Failed Kevlar ${ }^{\circledR}$ Composite (a) at Room Temperature; (b) after Cryogenic Exposure

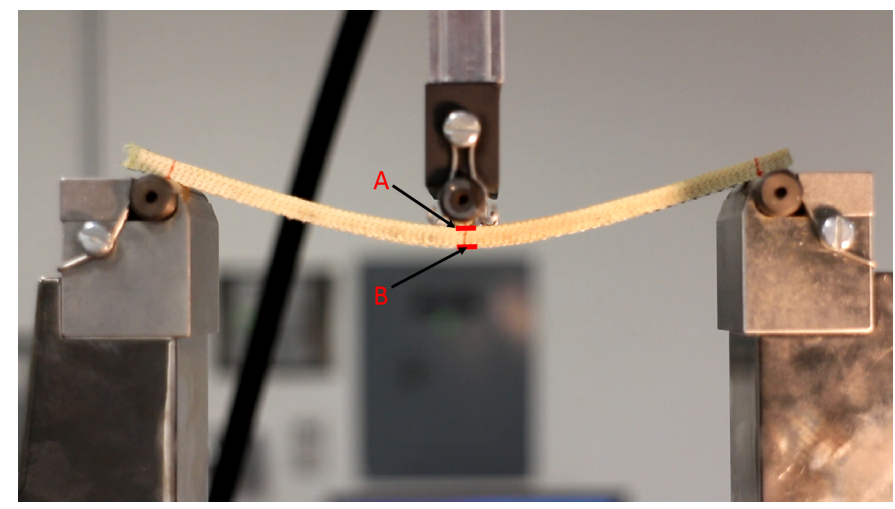

Figure 11: Three Point Bending Test of Kevlar ${ }^{\circledR}$ Fiber Specimen

cryogenic propellant tanks. Tensile and flexural experiments were followed to determine the thermo-mechanical responses of Kevlar ${ }^{\circledR}$ and carbon composites. This preliminary 
study indicated that woven thermosetting composites could have a potential use in cryogenic tanks. Further research is required to examine if any failure mechanisms, like delamination effects, occur due to hoop and corner strains caused by expansion and contraction when a constrained tank is subjected to cryogenic environment. Smart design of these composites would allow for lighter, stiffer, tougher and damage resistant propellant tanks. However, there are other aspects like extended and gradient exposure to cryogenic conditions that need to be studied before a definite conclusion can be reached.

\section{Acknowledgements}

The authors would like to acknowledge the financial sponsorship from the Campus Office for Undergraduate Research Initiative (COURI) at The University of Texas at El Paso (UTEP) for initial tests conducted. We would also like to acknowledge Dr. Asher Rubinstein for his support through the HBCU/MI Department of Defense Basic Research grant (Grant No.: W911NF-15-1-0430) to conduct this research.

\section{References}

[1] A. Belvin, S. K. Borowski, and J. Scott. The nuclear cryogenic propulsion stage. 2014.

[2] J. H. Vickers. Composite australia conference composite cryotank project structures for launch vehicles. 2013.

[3] S. Choi and B.V. Sankar. Fracture toughness of transverse cracks in graphite/epoxy laminates at cryogenic conditions. Composites Part B: Engineering, 38(2):193 - 200, 2007. ISSN 1359-8368. doi: http://dx.doi.org/10.1016/j.compositesb.2006.06.005.

[4] D.E. Steitz. Nasa tests game changing composite cryogenic fuel tank. NASA Web., 16 Dec. 2013.

[5] R. Sadeghian, S. Gangireddy, B. Minaie, and K. Hsiao. Manufacturing carbon nanofibers toughened polyester/glass fiber composites using vacuum assisted resin transfer molding for enhancing the mode-i delamination resistance. Composites Part A: applied science and manufacturing, 37 (10):1787-1795, 2006.

[6] A. J. Rodriguez, M. E. Guzman, C. Lim, and B. Minaie. Mechanical properties of carbon nanofiber/fiber-reinforced hierarchical polymer composites manufactured with multiscalereinforcement fabrics. Carbon, 49(3):937-948, 2011. 
[7] L. Lin, J. Lee, C. Hong, G. Yoo, and S. G. Advani. Preparation and characterization of layered silicate/glass fiber/epoxy hybrid nanocomposites via vacuum-assisted resin transfer molding (vartm). Composites Science and Technology, 66(13):2116-2125, 2006.

[8] A. D. Kelkar, J. S. Tate, and P. Chaphalkar. Performance evaluation of vartm manufactured textile composites for the aerospace and defense applications. Materials Science and Engineering: B, 132(1):126-128, 2006.

[9] B. V. Sankar and R. V Marrey. Analytical method for micromechanics of textile composites. Composites Science and Technology, 57(6):703-713, 1997.

[10] S. V. Lomov and I. Verpoest. Textile composite materials: Polymer matrix composites. Encyclopedia of Aerospace Engineering, 2010.

[11] S. B. Sharma and M. P. F. Sutcliffe. Draping of woven composites over irregular surfaces. In Proceedings of the 13th International Conference on Composite Materials (ICCM-13), Beijing, China, 2001.

[12] K. D. Potter. The influence of accurate stretch data for reinforcements on the production of complex structural mouldings: Part 1. deformation of aligned sheets and fabrics. Composites, 10 (3):161-167, 1979.

[13] V. T. Bechel, M. B. Fredin, S. L. Donaldson, R. Y. Kim, and J. D. Camping. Effect of stacking sequence on micro-cracking in a cryogenically cycled carbon/bismaleimide composite. Composites Part A: Applied Science and Manufacturing, 34(7):663-672, 2003.

[14] V. T. Bechel and R. Y. Kim. Damage trends in cryogenically cycled carbon/polymer composites. Composites science and technology, 64(12):1773-1784, 2004.

[15] V. T. Bechel, M. Negilski, and J. James. Limiting the permeability of composites for cryogenic applications. Composites Science and Technology, 66(13):2284-2295, 2006.

[16] J. Noh and J. Whitcomb. Effect of laminate design and loads on crack opening volume in laminates used in cryogenic tanks. Journal of Composites Technology and Research, 25(3):171-178, 2003.

[17] S. Roy, A. Utturkar, and A. Nair. Modeling and characterization of permeability and damage of graphite/epoxy at cryogenic temperature. In Proceedings of the 46th AIAA/ASME/ASCE/AHS/ASC SDM conference, Austin, TX, pages 2005-2088, 2005.

[18] T. Yokoeki, T. Aoki, and T. Ishikawa. Experimental cryogenic gas leakage through damaged composite laminates for propellant tank application. Journal of Spacecraft and rockets, 42(2): 363-366, 2005.

[19] V.T. Bechel. Helium flow through cryogenically pre-conditioned composite laminates. In Proceedings of the 50th SAMPE international symposium, Long Beach, CA, 2005.

[20] H. Kumazawa, T. Aoki, and I. Susuki. Analysis and experiment of gas leakage through composite laminates for propellant tanks. AIAA journal, 41(10):2037-2044, 2003.

[21] H. K. Rivers, J. G. Sikora, and S. N. Sankaran. Detection of hydrogen leakage in a composite sandwich structure at cryogenic temperature. Journal of spacecraft and rockets, 39(3):452-459, 2002.

[22] V. T. Bechel, J. D. Camping, and R. Y. Kim. Cryogenic/elevated temperature cycling induced leakage paths in pmcs. Composites Part B: Engineering, 36(2):171-182, 2005. 
[23] M. Gong, X.F. Wang, and J.H. Zhao. Experimental study on mechanical behavior of laminates at low temperature. Cryogenics, 47(1):1-7, 2007.

[24] S. Disdier, J.M. Rey, P. Pailler, and A.R. Bunsell. Helium permeation in composite materials for cryogenic application. Cryogenics, 38(1):135-142, 1998.

[25] D. Verstraete, P. Hendrick, P. Pilidis, and K. Ramsden. Hydrogen fuel tanks for subsonic transport aircraft. International journal of hydrogen energy, 35(20):11085-11098, 2010.

[26] S.M. Aceves, J. Martinez-Frias, and O. Garcia-Villazana. Analytical and experimental evaluation of insulated pressure vessels for cryogenic hydrogen storage. International Journal of Hydrogen Energy, 25(11):1075-1085, 2000.

[27] Y. Shindo, R. Wang, and K. Horiguchi. Analytical and experimental studies of short-beam interlaminar shear strength of g-10cr glass-cloth/epoxy laminates at cryogenic temperatures. Journal of engineering materials and technology, 123(1):112-118, 2001.

[28] M. S. Kumar, N. Sharma, and B.C. Ray. Microstructural and mechanical aspects of carbon/epoxy composites at liquid nitrogen temperature. Journal of Reinforced Plastics and Composites, 00(00), 2008.

[29] I. G. Tapeinos and S. Koussios. Experimental study on various liner materials for cryogenic liquid hydrogen storage. Materials, 6(1), 2013.

[30] T.J. Lu and N.A. Fleck. The thermal shock resistance of solids. Acta Materialia, 46(13):4755 4768, 1998. ISSN 1359-6454.

[31] D. Bender, J. Schuster, and D. Heider. Flow rate control during vacuum-assisted resin transfer molding (vartm) processing. Composites Science and Technology, 66(13):2265-2271, 2006.

[32] K. T. Hsiao, R. Mathur, S. G. Advani, J. W. Gillespie, and B. K. Fink. A closed form solution for flow during the vacuum assisted resin transfer molding process. Journal of manufacturing science and engineering, 122(3):463-475, 2000.

[33] B. W. Grimsley, P. Hubert, X. Song, R. J. Cano, A. C. Loos, and R. B. Pipes. Flow and compaction during the vacuum assisted resin transfer molding process. Proceedings of th International SAMPE Symposium, Seattle, WA, 2001.

[34] R. Mathuw, S. G. Advani, D. Heider, C. Hoffmann, J. W. Gillespie, and B. K. Fink. Flow front measurements and model validation in the vacuum assisted resin transfer molding process. Polymer Composites, 22(4):477-490, 2001.

[35] X. Sun, S. Li, and L. J. Lee. Mold filling analysis in vacuum-assisted resin transfer molding. part i: Scrimp based on a high-permeable medium. Polymer Composites, 19(6):807-817, 1998.

[36] J. Ju, B. D. Pickle, R. J. Morgan, and J. N. Reddy. An initial and progressive failure analysis for cryogenic composite fuel tank design. Journal of Composite Materials, 41(21):2545-2568, 2007.

[37] R. C. Goetz, R. S. Ryan, and A. F. Whitaker. Final report of the X-33 liquid hydrogen tank test investigation team. Marshall Space Flight Center, Huntsville, AL, 2000.

[38] ASTM Standard. D3039/D3039 M, 2008, Standard Test Method for Tensile Properties of Polymer Matrix Composite Materials, ASTM International, West Conshohocken, PA, 2003, . 
[39] ASTM Standard. D7264/D7264 M, 2007, Standard Test Method for Flexural Properties of Polymer Matrix Composite Materials, ASTM International, West Conshohocken, PA, 2003, .

[40] ASTM Standard. D2344/D2344 M, 2013, Standard Test Method for Short-Beam Strength of Polymer Matrix Composite Materials and Their Laminates, ASTM International, West Conshohocken, PA, 2003, .

[41] P. Prabhakar and A. M. Waas. Interaction between kinking and splitting in the compressive failure of unidirectional fiber reinforced laminated composites. Composite Structures, 98:85-92, 2013.

[42] P. Prabhakar and A. M. Waas. Micromechanical modeling to determine the compressive strength and failure mode interaction of multidirectional laminates. Composites Part A: Applied Science and Manufacturing, 50:11-21, 2013. 